\title{
Considerations for Setting Up an Order Entry System for Nuclear Medicine Tests
}

Narihiro Hara ${ }^{1,2}$, Masahisa Onoguchi ${ }^{2}$, Toshihiko Nishida ${ }^{1}$, Minoru Honda ${ }^{1}$, Osamu Houjou ${ }^{1}$, Masaru Yuhi ${ }^{3}$, Teruhiko Takayama ${ }^{2}$, and Jun Ueda ${ }^{4}$

${ }^{I}$ Department of Radiological Technology, Sumitomo Hospital, Osaka, Japan; ${ }^{2}$ Department of Health Sciences, Graduate School of Medical Sciences, Kanazawa University, Kodatsuno, Kanazawa, Japan; ${ }^{3}$ Division of System, Sumitomo Hospital, Osaka, Japan; and ${ }^{4}$ Department of Radiology, Sumitomo Hospital, Osaka, Japan

Integrating the Healthcare Enterprise-Japan (IHE-J) was established in Japan in 2001 and has been working to standardize health information and make it accessible on the basis of the fundamental Integrating Healthcare Enterprise (IHE) specifications. However, because specialized operations are used in nuclear medicine tests, online sharing of patient information and test order information from the order entry system as shown by the scheduled workflow (SWF) is difficult, making information inconsistent throughout the facility and uniform management of patient information impossible. Therefore, we examined the basic design (subsystem design) for order entry systems, which are considered an important aspect of information management for nuclear medicine tests and needs to be consistent with the system used throughout the rest of the facility. Methods: There are many items that are required by the subsystem when setting up an order entry system for nuclear medicine tests. Among these items, those that are the most important in the order entry system are constructed using exclusion settings, because of differences in the conditions for using radiopharmaceuticals and contrast agents and appointment frame settings for differences in the imaging method and test items. Conclusion: To establish uniform management of patient information for nuclear medicine tests throughout the facility, it is necessary to develop an order entry system with exclusion settings and appointment frames as standard features. Thereby, integration of health information with the Radiology Information System (RIS) or Picture Archiving Communication System (PACS) based on Digital Imaging Communications in Medicine (DICOM) standards and real-time health care assistance can be attained, achieving the IHE agenda of improving health care service and efficiently sharing information.

Key Words: nuclear medicine; order entry system; hospital total information system; radiology information system; Integrating the Healthcare Enterprise; picture archiving communication system

J Nucl Med Technol 2007; 35:259-271

DOI: 10.2967/jnmt.106.039818

Received Jan. 15, 2007; revision accepted Jun. 13, 2007.

For correspondence or reprints contact: Narihiro Hara, PhD, Sumitomo

Hospital, 5-3-20, Nakanoshima, Kita-ku, Osaka, 530-0005, Japan.

E-mail: hara-narihiro@sumitomo-hp.or.jp

COPYRIGHT @ 2007 by the Society of Nuclear Medicine, Inc.
W

ith the recent progress in the introduction of information technology, the health care industry has proceeded to establish Digital Imaging Communications in Medicine (DICOM) $(1,2)$ or Health Level Seven (HL7) $(3,4)$ for the standardization of medical information. In radiology departments, health information is being made accessible through the Radiology Information System (RIS) and Picture Archiving Communication System (PACS), which are based on DICOM standards (5-8). Integrating the Healthcare Enterprise (IHE), which was established in 1999 in America by the Radiological Society of North America and the Healthcare Information and Management Systems Society as a collaborative project to integrate health information for healthcare cooperation, has created a technical framework for message exchange specifications necessary for health information systems that are based on DICOM standards or HL7 standards, and these specifications have become widespread internationally (9-14). IHE-J was established in Japan in 2001 and has been working to standardize and make health information accessible based on the fundamental IHE specifications.

From the scheduled workflow (SWF) defined by IHE, the sharing of patient information online is considered a minimal condition for introducing and operating an information system for healthcare integration.

Classification according to the order entry system of orders issued in the scheduled workflow defined by IHE include consultation appointment order entry systems, general test order entry systems, and appointment test order entry systems (15) (Figs. 1A and 1B). A general test order entry system and an appointment test order entry system are needed in a radiology department.

By sharing patient information and test order information from the order entry system between Hospital total Information System (HIS)-RIS or RIS-Modality Worklist Management (MWM), the medical technician is assisted in imaging. Modality and information sharing also enable consistency of patient information and uniform management of image information throughout the facility. 
FIGURE 1. (A) Example of workflow of usual operation by IHE. (B) Flows of order entry system.

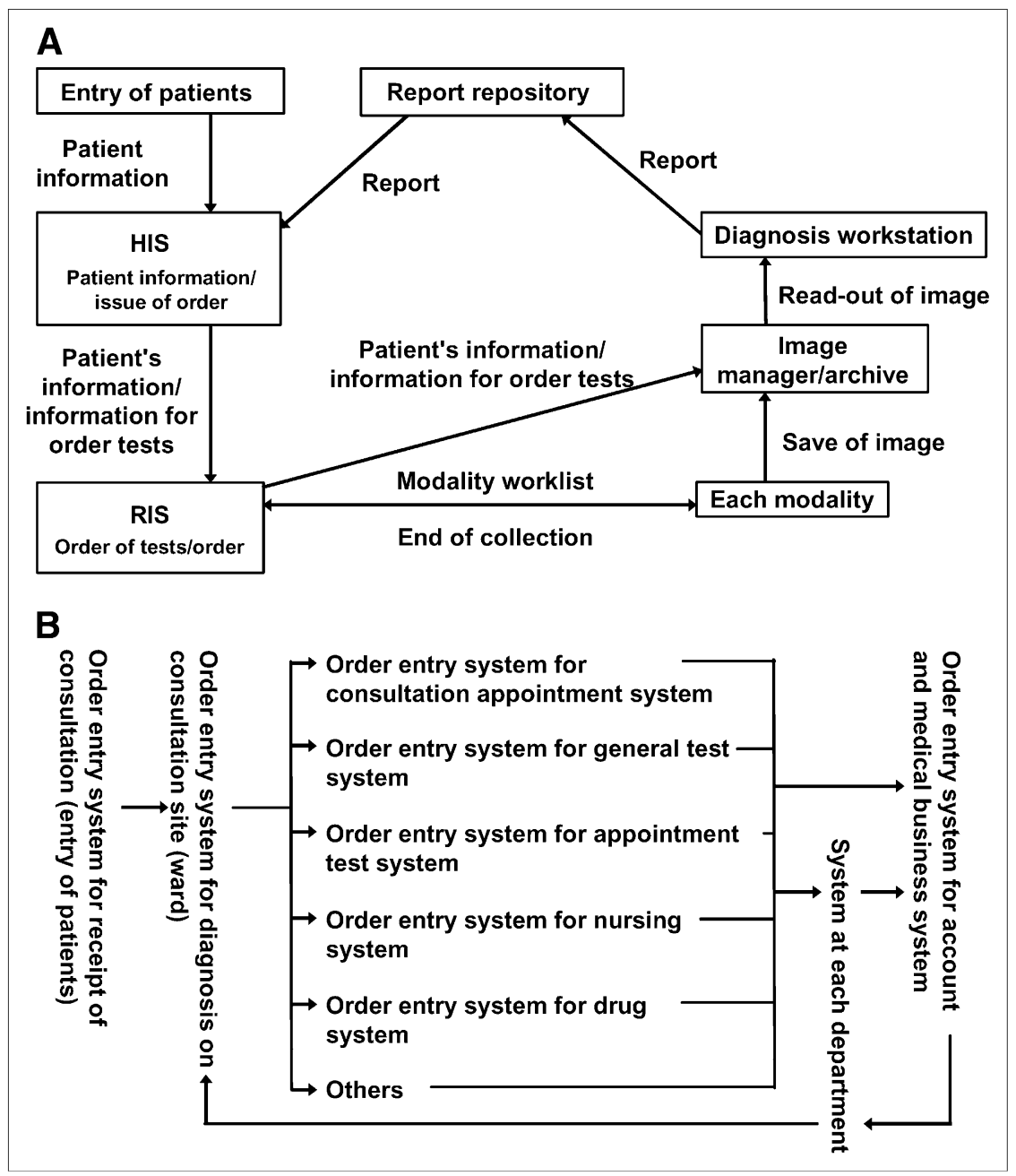

For general radiography or MRI and CT at the radiology department, patient information and test order information from the order entry system of the HIS is shared online with RIS and each MWM; By transmitting the information to the PACS or reporting system and HIS after completion of the test, information is consistent throughout the facility and patient information can be managed uniformly (16,17). However, because specialized operations are used in nuclear medicine tests, online sharing of patient information and test order information from the order entry system as shown by the SWF is difficult, making information inconsistent throughout the facility and uniform management of patient information impossible. For this reason, it is probable that vendors have not developed an order entry system that reflects the procedures and type of work involved in nuclear medicine tests. Therefore, we examined the exclusion settings and appointment frame settings for order entry systems, to determine those that would be important for information management in relation to nuclear medicine tests and consistent with the facility-wide system.

\section{MATERIALS AND METHODS}

\section{Development Software}

We developed our own software for an order entry system using Sumi ACCEL Win-ER, made by the Sumitomo Electric Industries Co.

\section{Setting Up the Order Entry System}

When setting up an order entry system, the medical technicians need to engage the external design (subsystem design) of a waterfall model/prototype model (Fig. 2). In the waterfall model/prototype model, a plan for the basic design of the system and an implementation plan need to be carefully considered when setting up the system. However, when actually introducing the system, it is current practice to conduct a study using the prototype model incorporated into the basic design. After considering the basic design, a study of the overall plan and subsystem is conducted based on the operational aspects of the external design. Thereafter, the module design of the internal design and the module production of the programming design are considered, the produced module is coded, and tests are conducted at each session. For nuclear medicine testing, it is essential for the operation of the order entry system that the medical technicians be involved in creating the subsystem design of the external system. 


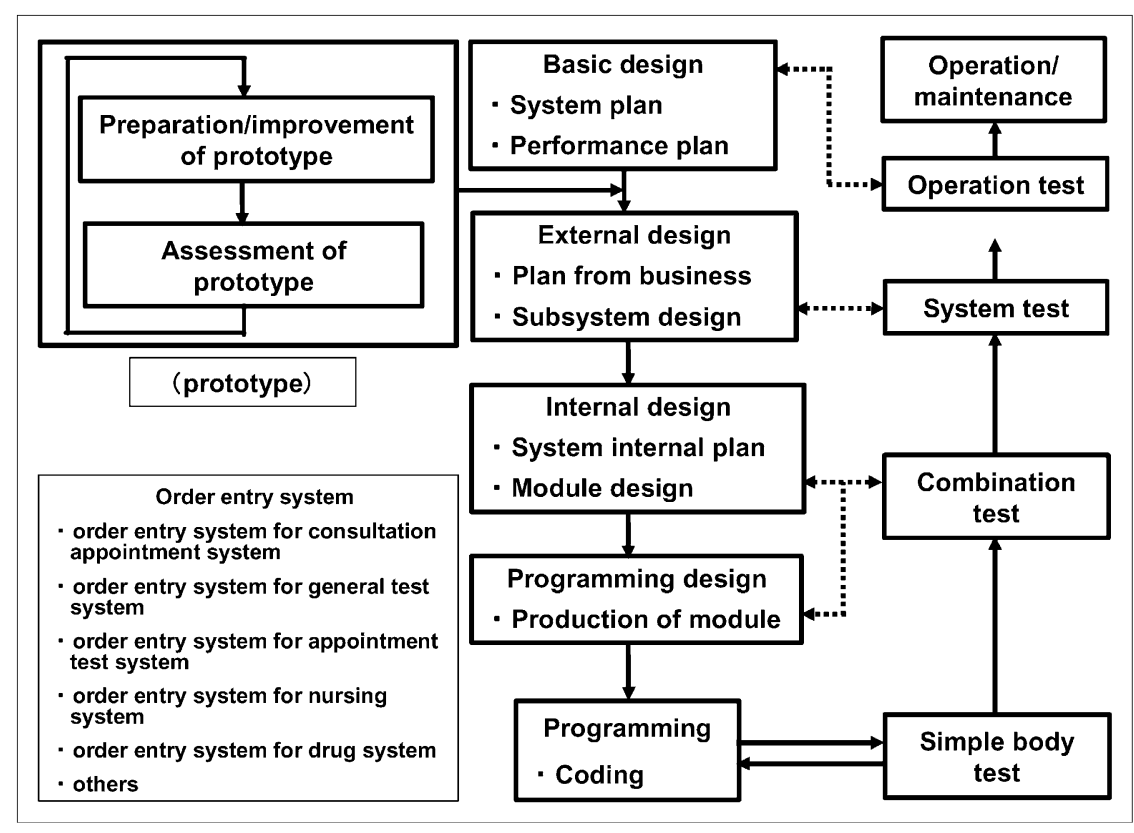

FIGURE 2. Construction process of order entry system (waterfall model/prototype model).

\section{Subsystem Design}

There are many items required by the order entry subsystem at the radiology department, including name settings for the modality and test items on the order screen, time settings for the test items, exclusion settings (interval settings), appointment frame setting, and the test ledger. Among these items, those that are the most important in an order entry system are exclusion settings because of differences in the conditions between radiopharmaceutical and contrast agent administration and appointment frame settings for differences in the imaging method and test items. We will describe a method of creating these items for nuclear medicine tests and MRI tests.

The subsystem design must be created before the exclusion settings. This involves setting the test items for each modality used on the order screen of the order entry system, setting the time required for each test item, and setting the group classification of test items for each modality and the classification of tests that can or cannot be started from the appointed hour for test items and groups.

Because specialized operations are used in nuclear medicine tests, settings for test items and the time required must be classified by the time needed for collection and the injection time. There are 40 test items set as needing time for collection, including thyroid ( ${ }^{99 \mathrm{~m}} \mathrm{Tc}$-pertechnetate $\left(\left[{ }^{99} \mathrm{mcO}_{4}{ }^{-}\right]\right), 30 \mathrm{~min}$; myocardial fatty acid metabolism $\left({ }^{123} \mathrm{I}-\beta\right.$-methyl-iodophenylpentadecanoic acid $\left[{ }^{123} \mathrm{I}-\right.$ BMIPP]), $30 \mathrm{~min}$; and renal function/renal plasma flow (RPF) ( ${ }^{99 \mathrm{~m}}$ Tc-mercaptoacetyltriglycine [99m Tc-MAG3]), $30 \mathrm{~min}$. There are 19 test items set as needing time for injection, including bone adult/whole body ( ${ }^{99 \mathrm{~m}} \mathrm{Tc}$-hydroxymethylenediphosphonate [ ${ }^{99 \mathrm{~m}} \mathrm{Tc}-$ HMDP] $),{ }^{67} \mathrm{Ga}$ adult/whole body $\left({ }^{67} \mathrm{Ga}\right.$-citrate $), 10 \mathrm{~min}$; and adosterol ( ${ }^{131}$ I-adosterol), $10 \mathrm{~min}$, for a total of 59 test items (Table 1).

Groups of test items can be classified into 16 groups, including the ${ }^{99 \mathrm{~m} T c}$ drug product group, ${ }^{67} \mathrm{Ga}$ drug product group, and cerebral-blood-flow (CBF) drug product group (Table 1).

Test items are classified as belonging to groups such as the

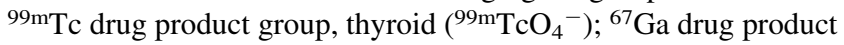
group, ${ }^{67} \mathrm{Ga}$ adult/whole body $\left({ }^{67} \mathrm{Ga}\right.$-citrate); and $\mathrm{CBF}$ drug product group, CBF ( ${ }^{123} \mathrm{I}-N$-isopropyl-p-iodoamphetamine $\left[{ }^{123} \mathrm{I}-\right.$ IMP]) (Table 1).
Classifications of tests that can or cannot start from the time of scheduling differ in nuclear medicine depending on the test item and group (Table 1).

\section{Exclusion Settings}

Classification. Methods of exclusion setting include setting between test item groups conducted between each test item and groups classified by each test item, setting between groups classified by each test item, and setting between test items conducted between each test item.

Settings Between Test Item Groups. In this method, exclusion settings are configured for each group to which the subject test items belong, with the ordered test item as the standard. Excluded values for settings between test item groups are shown in Table 2 Top, Middle, and Bottom. The number of excluded values set between MRI tests was 180 (Table 2 Top). The number of excluded values set between nuclear medicine tests was 1,824 in this study (Table 2 Middle). The number of excluded values set between nuclear medicine tests and MRI tests was 1,554 (Table 2 Bottom).

As an example of the method of setting, the set values for MRI tests were zero for the plain MRI group and zero for the contrastenhanced MRI group, with plain MRI of the head belonging to the plain MRI group as the standard (Fig. 3A). The set values for nuclear test items were the subsequent $4 \mathrm{~d}$ and the previous $4 \mathrm{~d}$ for the ${ }^{67} \mathrm{Ga}$ drug product group and the subsequent $2 \mathrm{~d}$ and the previous $2 \mathrm{~d}$ for the $\mathrm{CBF}$ drug product group, with thyroid $\left({ }^{99} \mathrm{mcO}_{4}{ }^{-}\right)$belonging to the ${ }^{99 \mathrm{~m}} \mathrm{Tc}$ drug product group as the standard (Fig. 3B). The set values between nuclear medicine tests and MRI tests must be set for all MRI test groups, with all test items belonging to nuclear medicine tests, such as thyroid scan $\left({ }^{99} \mathrm{mcO}_{4}{ }^{-}\right)$as the standard, and for all nuclear medicine test groups, with all test items belonging to MRI tests, such as plain MRI of the head, as the standard (Fig. 3C).

Settings Between Groups. As the method for setting between groups, exclusion settings are configured for each group to which the subject test items belong, with the group to which the ordered test item belongs as the standard. Excluded values for settings between groups are shown in Table 3 Top, Middle, and Bottom). 
TABLE 1

Subsystem Design of Nuclear Scanning

\begin{tabular}{|c|c|c|c|c|}
\hline \multirow[b]{2}{*}{ Group classification } & \multirow[b]{2}{*}{ Test item (NM) } & \multicolumn{2}{|c|}{ Time required } & \multirow{2}{*}{$\begin{array}{c}\text { Presence or absence } \\
\text { of start from } \\
\text { time appointed }\end{array}$} \\
\hline & & $\begin{array}{l}\text { Collecting } \\
\text { time }\end{array}$ & $\begin{array}{l}\text { Injection } \\
\text { time }\end{array}$ & \\
\hline \multirow[t]{16}{*}{ 99mTc drug pro.g } & Thyroid $\left(99 \mathrm{~m} \mathrm{TcO}_{4}{ }^{-}\right)$ & 30 & - & 0 \\
\hline & Parathyroid (99mTc-MIBI) & 30 & - & 0 \\
\hline & Salivary gland $\left({ }^{99 m} \mathrm{TcO}_{4}{ }^{-}\right)$ & 30 & - & 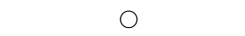 \\
\hline & Brain $\left({ }^{99 m} \mathrm{Tc}-\mathrm{ECD}\right)$ & 30 & - & $\bigcirc$ \\
\hline & Head vein angiogram $\left({ }^{99 m} \mathrm{TcO}_{4}{ }^{-}\right)$ & 30 & - & $\bigcirc$ \\
\hline & Trunk vein angiogram $\left({ }^{99 \mathrm{~m}} \mathrm{TcO}_{4}{ }^{-}\right)$ & 30 & - & $\bigcirc$ \\
\hline & Upper limb (right) vein angiogram $\left({ }^{99 \mathrm{~m}} \mathrm{TcO}_{4}{ }^{-}\right)$ & 30 & - & $\bigcirc$ \\
\hline & Upper limb (left) vein angiogram $\left({ }^{99 \mathrm{~m}_{\mathrm{TcO}}}{ }^{-}\right)$ & 30 & - & $\bigcirc$ \\
\hline & Pelvic vein angiogram $\left({ }^{99 \mathrm{mTcO}_{4}}{ }^{-}\right)$ & 30 & - & $\bigcirc$ \\
\hline & Lower limb vein angiogram $\left({ }^{99 m} \mathrm{TcO}_{4}{ }^{-}\right)$ & 30 & - & $\bigcirc$ \\
\hline & Head artery angiogram $\left({ }^{99 m} \mathrm{TcO}_{4}{ }^{-}\right)$ & 30 & - & $\bigcirc$ \\
\hline & Trunk artery angiogram $\left({ }^{99 m} \mathrm{TcO}_{4}{ }^{-}\right)$ & 30 & - & $\bigcirc$ \\
\hline & Upper limb (right) artery angiogram $\left({ }^{99} \mathrm{TcO}_{4}{ }^{-}\right)$ & 30 & - & $\bigcirc$ \\
\hline & Upper limb (left) artery angiogram $\left({ }^{99 \mathrm{~m}} \mathrm{TCO}_{4}{ }^{-}\right)$ & 30 & - & $\bigcirc$ \\
\hline & Pelvic artery angiogram $\left({ }^{99 \mathrm{~m}_{\mathrm{TcO}}}{ }_{4}^{-}\right)$ & 30 & - & $\bigcirc$ \\
\hline & Lower limb artery angiogram $\left({ }^{\left.99 \mathrm{~m} \mathrm{TcO}_{4}{ }^{-}\right)}\right.$ & 30 & - & $\bigcirc$ \\
\hline \multirow[t]{2}{*}{ Bone drug pro.g } & Bone adult/whole body ( ${ }^{99 m}$ Tc-HMDP) & - & 10 & $\times$ \\
\hline & Bone child/whole body ( ${ }^{99 m}$ Tc-HMDP) & - & 10 & $\times$ \\
\hline \multirow[t]{2}{*}{${ }^{67} \mathrm{Ga}$ drug pro.g } & ${ }^{67} \mathrm{Ga}$ adult/whole body ( ${ }^{67} \mathrm{Ga}$-citrate) & - & 10 & $\times$ \\
\hline & ${ }^{67} \mathrm{Ga}$ child/whole body ( ${ }^{67} \mathrm{Ga}$-citrate) & - & 10 & $\times$ \\
\hline \multirow[t]{2}{*}{${ }^{131}$ I drug pro.g } & Adosterol ( ${ }^{131}$ I-adosterol) & - & 10 & $\times$ \\
\hline & Pheo scinitigraphy ( ${ }^{131}$ I-Pheo-MIBG) & - & 10 & $\times$ \\
\hline \multirow[t]{3}{*}{${ }^{201} \mathrm{TI}$ drug pro.g } & Thyroid $\left({ }^{201} \mathrm{TICl}\right)$ & 30 & - & $\bigcirc$ \\
\hline & Tumor $(201 \mathrm{TICl})$ & 30 & - & $\bigcirc$ \\
\hline & Myocardial blood flow at resting $\left({ }^{201} \mathrm{TICl}\right)$ & 30 & - & $\bigcirc$ \\
\hline Intake rate in thyroid drug pro.g & Intake rate in thyroid $\left(\mathrm{Na}^{123} \mid\right.$ capsule) & - & 10 & $\times$ \\
\hline \multirow[t]{2}{*}{${ }^{99 \mathrm{~m} T \mathrm{c}}+{ }^{67} \mathrm{Ga}$ drug pro.g } & Bone $+{ }^{67} \mathrm{Ga}$ adult/whole body $\left({ }^{99 \mathrm{mTc}} \mathrm{T}-\mathrm{HMDP}+{ }^{67} \mathrm{Ga}\right.$-citrate) & - & 10 & $\times$ \\
\hline & Bone $+{ }^{67} \mathrm{Ga}$ child/whole body $\left({ }^{99 \mathrm{mT}} \mathrm{T}-\mathrm{HMDP}+{ }^{67} \mathrm{Ga}\right.$-citrate) & - & 10 & $\times$ \\
\hline \multirow[t]{2}{*}{ 123/ drug pro.g } & Myocardial fatty acid metabolism ( $\left.{ }^{123} \mid-B M I P P\right)$ & 40 & & $\bigcirc$ \\
\hline & Myocardial sympathetic nerve activity ( ${ }^{123}$ I-MIBG) & 40 & & $\bigcirc$ \\
\hline \multirow[t]{5}{*}{ Myocardial drug pro.g } & Myocardial blood flow at resting (99mTc-MIBI) & - & 10 & $\times$ \\
\hline & Myocardial blood flow movement (99mTc-TF) & 60 & - & $\bigcirc$ \\
\hline & Myocardial blood flow movement $\left({ }^{201} \mathrm{TICl}\right)$ & 60 & - & $\bigcirc$ \\
\hline & Myocardial blood flow movement drug product ( ${ }^{99 m T c-T F) ~}$ & 50 & - & $\bigcirc$ \\
\hline & Myocardial pool (99mTc-HAS-D) & 60 & - & $\bigcirc$ \\
\hline \multirow[t]{2}{*}{ Respiratory system drug pro.g } & Lung blood flow ( ${ }^{99 m}$ Tc-MAA) & 30 & - & $\bigcirc$ \\
\hline & Lung ventilation ( ${ }^{81 \mathrm{~m}} \mathrm{Kr}$ gas) & 30 & - & 0 \\
\hline \multirow[t]{2}{*}{ CBF drug pro.g } & CBF (123I-IMP) & 60 & - & 0 \\
\hline & Load of CBF (123/-IMP) & 120 & - & 0 \\
\hline \multirow[t]{6}{*}{ Digestive system drug pro.g } & Liver function ( ${ }^{99 m T c-G S A)}$ & 30 & - & $\bigcirc$ \\
\hline & Liver/biliary tract ( $\left.{ }^{99 m} \mathrm{Tc}-\mathrm{PMT}\right)$ & 30 & - & $\bigcirc$ \\
\hline & Liver ( ${ }^{99 m}$ Tc-Sn-colloid) & 30 & - & $\bigcirc$ \\
\hline & Spleen ( ${ }^{99 m}$ Tc-Sn-colloid) & 30 & - & $\bigcirc$ \\
\hline & Gastrointestinal bleeding ( ${ }^{99 m}$ Tc-HAS-D) & 60 & - & $\bigcirc$ \\
\hline & Ectopic gastic mucosa $\left({ }^{99 m \mathrm{TcO}_{4}}{ }^{-}\right)$ & 60 & - & $\bigcirc$ \\
\hline \multirow[t]{3}{*}{ Urinary system drug pro.g } & Renal function/RPF (99mTc-MAG3) & 30 & - & $\bigcirc$ \\
\hline & Renal function/GFR (99mTc-DTPA) & 30 & - & $\bigcirc$ \\
\hline & Kidney ( ${ }^{99 m}$ Tc-DMSA) & 30 & - & 0 \\
\hline${ }^{111}$ In drug pro.g & Brain tank $\left.\left({ }^{111} \operatorname{lnCl}\right)_{3}\right)$ & - & 10 & $\times$ \\
\hline & Encephalon ( $\left.{ }^{111} \ln -\mathrm{DTPA}\right)$ & - & 10 & $\times$ \\
\hline Hematopoietic organ drug pro.g & Amount of circulating blood & 10 & - & $\bigcirc$ \\
\hline & Erythrocyte life span & 10 & - & 0 \\
\hline Later collection group & Adosterol at a later date & - & 30 & $\times$ \\
\hline & ${ }^{67} \mathrm{Ga}$ photograph adult at a later date & - & 60 & $\times$ \\
\hline & Intake rate in thyroid at a later date & - & 30 & $\times$ \\
\hline & Pheo scinitigraphy at a later date & - & 30 & $\times$ \\
\hline & Gastrointestinal bleeding at a later date & - & 30 & $\times$ \\
\hline & Bone marrow at a later date & - & 60 & $\times$ \\
\hline & Brain tank at a later date & - & 60 & $\times$ \\
\hline
\end{tabular}

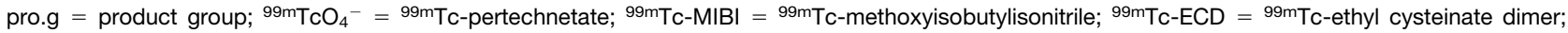
${ }^{99 m T c-T F ~=~ 99 m T c-t e t r o f o s m i n ; ~}{ }^{99 m T c-H A S-D ~=~ 99 m T c-d i e t h y l e n e t r i a m i n e ~ p e n t a a c e t i c ~ a c i d ~ h u m a n ~ s e r u m ~ a l b u m i n ; ~}{ }^{99 m}$ Tc-HAS-D = 99mTc-diethylenetriamine pentaacetic acid human serum albumin; $99 \mathrm{mTc}-\mathrm{MMA}={ }^{99 \mathrm{~m} T c-m a c r o a g g r e t a t e d ~ a l b u m i n ;}{ }^{81 \mathrm{~m}} \mathrm{Kr}$ gas $=\mathrm{krypton}-81 \mathrm{~m}$ gas; $99 \mathrm{mTc}-\mathrm{GSA}={ }^{99 m T c-g a l a c t o s y l}$

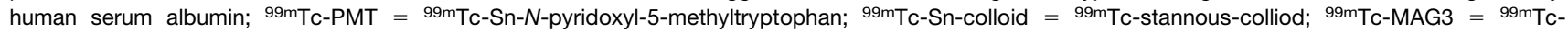

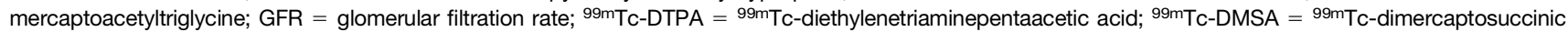
acid; ${ }^{111} \mathrm{InCl}{ }_{3}={ }^{111} \mathrm{In}$-chloride; ${ }^{111} \mathrm{In}$-DTPA $={ }^{111} \mathrm{In}$-diethylenetriaminepentaacetic acid; $\mathrm{NM}=$ nuclear medicine. 
TABLE 2

Confined Setting of Test Items Between Groups

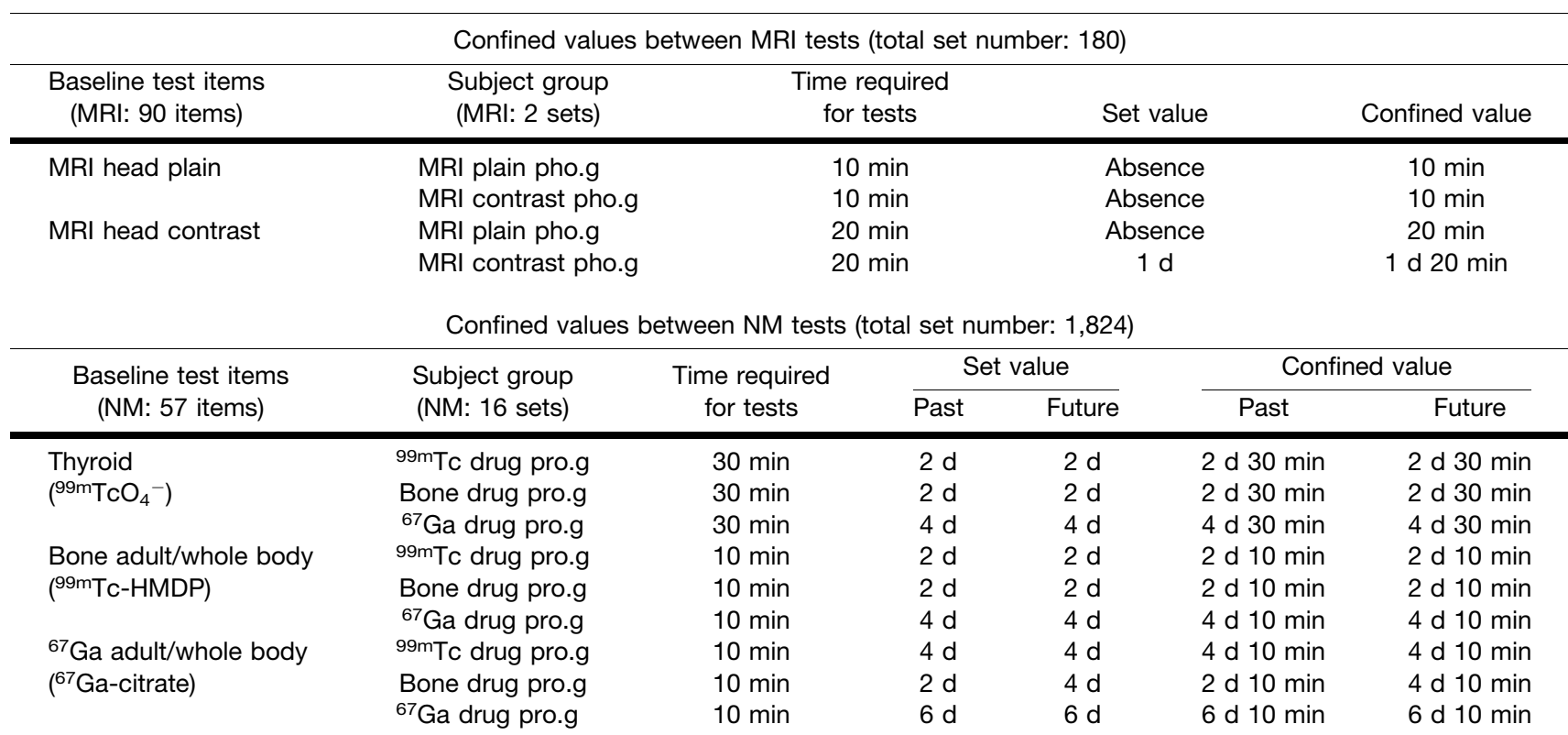

Confined values between NM tests and MRI tests (total set number: 1,554)

\begin{tabular}{|c|c|c|c|c|}
\hline $\begin{array}{c}\text { Baseline test items } \\
\text { (NM: } 57 \text { items) (MRI: } 90 \text { items) }\end{array}$ & $\begin{array}{c}\text { Subject group } \\
\text { (MRI: } 2 \text { sets) (NM: } 16 \text { sets) }\end{array}$ & $\begin{array}{l}\text { Time required } \\
\text { for tests }\end{array}$ & Set value & Confined value \\
\hline Thyroid & MRI plain pho.g & $30 \mathrm{~min}$ & $1 \mathrm{~h}$ & $1 \mathrm{~h} 30 \mathrm{~min}$ \\
\hline$\left({ }^{99 \mathrm{~m}} \mathrm{Tc}-\mathrm{O}_{4}{ }^{-}\right)$ & MRI contrast pho.g & $30 \mathrm{~min}$ & $1 \mathrm{~h}$ & $1 \mathrm{~h} 30 \mathrm{~min}$ \\
\hline Bone adult/whole body & MRI plain pho.g & $10 \mathrm{~min}$ & Absence & $10 \mathrm{~min}$ \\
\hline (99mTc-HMDP) & MRI contrast pho.g & $10 \mathrm{~min}$ & Absence & $10 \mathrm{~min}$ \\
\hline${ }^{67} \mathrm{Ga}$ adult/whole body & MRI plain pho.g & $10 \mathrm{~min}$ & Absence & $10 \mathrm{~min}$ \\
\hline ( ${ }^{67} \mathrm{Ga}-$ citrate) & MRI contrast pho.g & $10 \mathrm{~min}$ & Absence & $10 \mathrm{~min}$ \\
\hline \multirow[t]{3}{*}{ MRI head plain } & ${ }^{99 m}$ Tc drug pho.g & $10 \mathrm{~min}$ & $1 \mathrm{~h}$ & $1 \mathrm{~h} 10 \mathrm{~min}$ \\
\hline & Bone drug pro.g & $10 \mathrm{~min}$ & Absence & $10 \mathrm{~min}$ \\
\hline & ${ }^{67} \mathrm{Ga}$ drug pro.g & $10 \mathrm{~min}$ & Absence & $10 \mathrm{~min}$ \\
\hline \multirow[t]{3}{*}{ MRI head contrast } & 99mTc drug pro.g & $20 \mathrm{~min}$ & $1 \mathrm{~h}$ & $1 \mathrm{~h} 20 \mathrm{~min}$ \\
\hline & Bone drug pro.g & $20 \min$ & Absence & $10 \mathrm{~min}$ \\
\hline & ${ }^{67} \mathrm{Ga}$ drug pro.g & $20 \mathrm{~min}$ & Absence & $10 \mathrm{~min}$ \\
\hline
\end{tabular}

pho.g $=$ photography group; $\mathrm{NM}=$ nuclear medicine; pro.g = product group.

The number of excluded values set between MRI tests was 4 (Table 3 Top). The number of excluded values set between nuclear medicine tests was 512 in this study (Table 3 Middle). The number of excluded values set between nuclear medicine tests and MRI tests was 64 (Table 3 Bottom).

Settings Between Test Items. As the method for establishing settings between test items, exclusion settings are configured for each test item, with the ordered test item as the standard. Excluded values for settings between test items are shown in Table 4 Top, Middle, and Bottom. The number of excluded values set between MRI tests was 8,100 (Table 4 Top). The number of excluded values set between nuclear medicine tests was 6,498 in this study (Table 4 Middle). The number of excluded values set between nuclear medicine tests and MRI tests was 10,260 (Table 4 Bottom).

Arrangement of Excluded Values. In setting the excluded values, there are excluded values that do not include the time required for the test (excluded value $=$ set value) and excluded values that do include the time required for the test (excluded value $=$ standard time required for test item + set value). In our study, we set excluded values not including the time required for the test as the settings between groups and excluded values including the time required for the test as the settings between test item groups and between test items. The time required for the test was an excluded value for test items without a set value.

\section{Appointment Frame Settings}

Classification. Methods for setting appointment frames include time series setting and group setting.

In group setting, one or more frames is set for the modality of the appointment frame, and appointment frames are set on the basis of the acquisition frame of test appointments during the routine work from Monday to Friday and the types of operation. The subject test is 


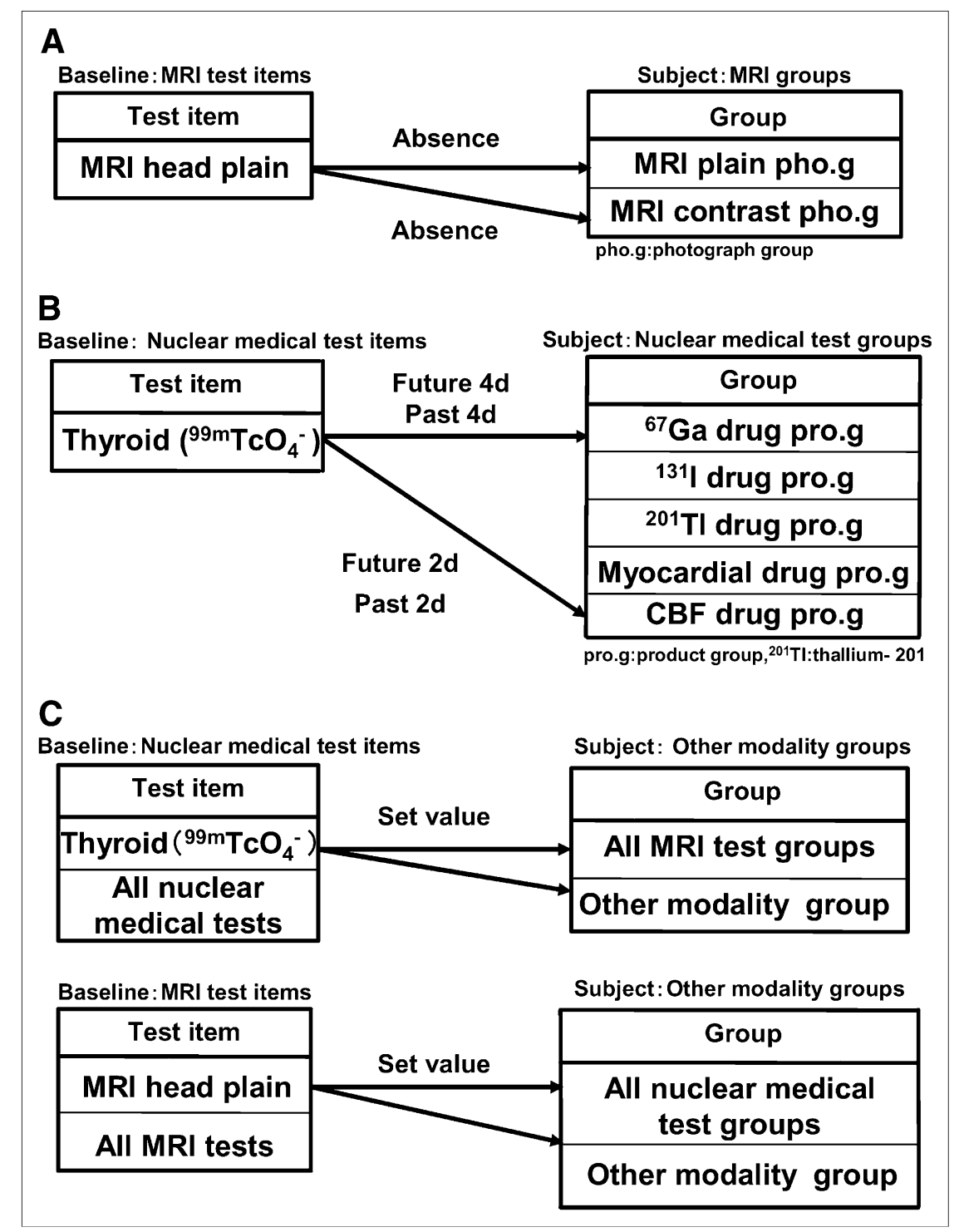

FIGURE 3. Example: Setting between test item groups. Setting of confinement using each test item as the baseline subject. (A) MRI test. (B) Nuclear medical test. (C) Nuclear medical test and MRI test.

a modality in which the test cannot be started at the scheduled time depending on the test item (Table 1). In creating appointment frame settings, it is also necessary to set the name of the appointment frame and the test items for the appointment frame (Table 5).

Group Settings for Appointment Frames. Because nuclear medicine tests cannot be started at the scheduled time depending on the test item, it would be inconvenient for operations if time series settings were used as they are for MRI tests. Therefore, for nuclear medicine tests, it is necessary to set appointment frames as group settings. Examples of appointment frames are shown in Figure 4. The appointment frame names would be bone test frame, brain test frame, and circulatory-resting test frame, for a total of 19 appointed test frames (Table 5). Because it is necessary to place an order for radiopharmaceuticals and confirm the operational status of the test apparatus, the testing room is contacted when the test is entered in the emergency test frame or demand test frame. Test items for appointment frames would include bone test frame, bone adult/whole body ( ${ }^{99} \mathrm{~m}$ Tc-HMDP); brain test frame, CBF $\left({ }^{123} \mathrm{I}-\right.$
IMP); and circulatory organ-resting test frame, myocardial fatty acid metabolism ( ${ }^{123} \mathrm{I}$-BMIPP) (Table 5).

\section{RESULTS}

\section{Relation of Exclusion Settings to Appointment Frame Settings}

The appointment frame for the ordered item is displayed on the order screen, the appointment time and date of the test are acquired on the order side on the basis of the appointment frame, and the exclusion settings are configured between other ordered test items with the appointment time and date as the standard. In the case of nuclear medicine tests, exclusion settings are also configured for previously ordered nuclear medicine tests. The methods of exclusion setting against test items that are ordered are (a) settings between test item groups: exclusion settings for each group to which the 
TABLE 3

Setting of Confined Values Between Groups

\begin{tabular}{|c|c|c|c|}
\hline \multicolumn{4}{|c|}{ Confined values between MRI tests (total set number: 4) } \\
\hline $\begin{array}{l}\text { Baseline group } \\
\text { (MRI: } 2 \text { settings) }\end{array}$ & \multicolumn{2}{|c|}{$\begin{array}{l}\text { Subject group } \\
\text { (NM: } 2 \text { settings) }\end{array}$} & $\begin{array}{l}\text { Confined } \\
\text { value }\end{array}$ \\
\hline \multirow[t]{2}{*}{ MRI plain pho.g } & \multirow{2}{*}{\multicolumn{2}{|c|}{$\begin{array}{l}\text { MRI plain pho.g } \\
\text { MRI contrast pho.g }\end{array}$}} & $1 \mathrm{~h}$ \\
\hline & & & $1 \mathrm{~h}$ \\
\hline \multirow[t]{2}{*}{ MRI contrast pho.g } & \multicolumn{2}{|c|}{ MRI plain pho.g } & $1 \mathrm{~h}$ \\
\hline & \multicolumn{2}{|c|}{ MRI contrast pho.g } & $1 \mathrm{~d}$ \\
\hline \multicolumn{4}{|c|}{ Confined values between NM tests (total set number: 512 ) } \\
\hline \multirow{2}{*}{$\begin{array}{l}\text { Baseline group } \\
\text { (NM: } 16 \text { settings) }\end{array}$} & \multirow{2}{*}{$\begin{array}{l}\text { Subject group } \\
\text { (NM: } 16 \text { settings) }\end{array}$} & \multicolumn{2}{|c|}{ Confined value } \\
\hline & & Past & Future \\
\hline \multirow[t]{3}{*}{ 99mTc drug pro.g } & 99mTc drug pro.g & $2 d$ & $2 d$ \\
\hline & Bone drug pro.g & $2 d$ & $2 d$ \\
\hline & ${ }^{67} \mathrm{Ga}$ drug pro.g & $4 \mathrm{~d}$ & $4 d$ \\
\hline \multirow[t]{3}{*}{ Bone drug pro.g } & 99mTc drug pro.g & $2 d$ & $2 d$ \\
\hline & Bone drug pro.g & $2 \mathrm{~d}$ & $2 d$ \\
\hline & ${ }^{67} \mathrm{Ga}$ drug pro.g & $4 \mathrm{~d}$ & $4 d$ \\
\hline \multirow[t]{3}{*}{${ }^{67} \mathrm{Ga}$ drug pro.g } & 99mTc drug pro.g & $2 d$ & $4 \mathrm{~d}$ \\
\hline & Bone drug pro.g & $2 d$ & $4 d$ \\
\hline & ${ }^{67} \mathrm{Ga}$ drug pro.g & $6 \mathrm{~d}$ & $6 d$ \\
\hline
\end{tabular}

Confined values between NM tests and MRI tests (total set number: 64)

\begin{tabular}{clc}
\hline $\begin{array}{c}\text { Baseline group } \\
\text { (NM: 16 settings) }\end{array}$ & $\begin{array}{c}\text { Subject group } \\
\text { (MRI: 2 settings) }\end{array}$ & $\begin{array}{c}\text { Confined } \\
\text { value }\end{array}$ \\
\hline (MRI: 2 settings) & (NM: 16 settings) & $1 \mathrm{~h}$ \\
\hline 99mTc drug pro.g & MRI plain pho.g & $1 \mathrm{~h}$ \\
& MRI contrast pho.g & $1 \mathrm{~h}$ \\
Bone drug pro.g & MRI plain pho.g & $1 \mathrm{~h}$ \\
& MRI contrast pho.g & $1 \mathrm{~h}$ \\
MRI plain pho.g & $99 m$ Tc drug pro.g & $1 \mathrm{~h}$ \\
& Bone drug pro.g & $1 \mathrm{~h}$ \\
MRI contrast pho.g & $99 m$ Tc drug pro.g & $1 \mathrm{~h}$ \\
& Bone drug pro.g &
\end{tabular}

$\mathrm{NM}$ = nuclear medicine; pho.g = photography group; pro.g = product group.

subject test item belongs, with the ordered test item as the standard; (b) settings between groups: exclusion settings for each group to which the subject test item belongs, with the group to which the ordered test item belongs as the standard; (c) settings between test items: exclusion settings for each test item, with the ordered test item as the standard.

\section{Methods for Obtaining Appointment}

I. Nuclear Medicine Tests. The method of scheduling an appointment for a nuclear medicine test is shown with an example (Fig. 5). If in the bone test frame, patient $\mathrm{A}$ has an appointment for bone adult/whole body ( ${ }^{99 \mathrm{~m}} \mathrm{Tc}-\mathrm{HMDP}$ ) (required time, $10 \mathrm{~min}$ ) at $0900 \mathrm{~h}$ on October 20, patient $\mathrm{C}$ has an appointment for bone adult/whole body ( ${ }^{99 \mathrm{~m} T \mathrm{Tc}-\mathrm{HMDP})}$ (required time, $10 \mathrm{~min}$ ) at $1100 \mathrm{~h}$ on October 20, and in the brain test frame, patient $\mathrm{B}$ is scheduled for CBF (123 I-IMP) at $0900 \mathrm{~h}$ on October 20 , the CBF ( ${ }^{123} \mathrm{I}-\mathrm{IMP}$ ) test for patient $\mathrm{B}$ can be conducted while patient $\mathrm{A}$ is injected for the bone adult/ whole body ( $\left.{ }^{99 \mathrm{~m}} \mathrm{Tc}-\mathrm{HMDP}\right)$, and the apparatus can be operated efficiently, and the test can be conducted at the appointed hour for patient $\mathrm{C}$. Because exclusion settings are used between the test item groups, patients $\mathrm{A}, \mathrm{B}$, and $\mathrm{C}$ can each be scheduled $2 \mathrm{~d}$ later, and scheduling can be conducted on open appointment frames for October 21 or later. Thus, test frame settings based on the types of operations and the operation time of the apparatus are necessary for nuclear medicine test items.

II. Nuclear Medicine Tests and MRI Tests. The method of scheduling an appointment for nuclear medicine tests and MRI tests is shown with an example (Fig. 6). If patient A is scheduled for nuclear medicine and MRI tests of bone adult/ whole body ( ${ }^{99 \mathrm{~m} T c-H M D P), ~ C B F ~(123 I-I M P), ~ M R I ~ o f ~ t h e ~}$ abdomen liver/spleen, and contrast-enhanced MRI of the head, these can be scheduled as bone adult/whole body ( ${ }^{99 \mathrm{~m}} \mathrm{Tc}-\mathrm{HMDP}$ ) (required time, $10 \mathrm{~min}$ ) at $0900 \mathrm{~h}$ on October 20, MRI of the abdomen liver/spleen (required time, $20 \mathrm{~min}$ ) at $0910 \mathrm{~h}$ on October 20, CBF ( ${ }^{123} \mathrm{I}$-IMP) (required time, 60 $\mathrm{min}$ ) at $0900 \mathrm{~h}$ on October 22, and contrast-enhanced MRI of the head (required time, $20 \mathrm{~min}$ ) at $1100 \mathrm{~h}$ on October 22, on the basis of the exclusion settings (settings between test item groups). However, although the exclusion settings would allow scheduling of the contrast-enhanced MRI of the head (required time, $20 \mathrm{~min}$ ) for an open appointment frame on October 21 or later, if patient A prefers that the test be conducted on the same day as the CBF ( ${ }^{123} \mathrm{I}$-IMP) (required time, $60 \mathrm{~min}$ ), an appointment for contrast-enhanced MRI of the head (required time, $20 \mathrm{~min}$ ) on the same day is also possible.

\section{DISCUSSION}

DICOM is becoming increasingly widespread in the health industry. On the basis of the SWF defined by IHE, when planning to introduce and operate information systems for healthcare integration, online sharing of information — such as patient information and order entry system information throughout the facility-is considered to be a minimal condition.

When considering the introduction of an order entry system, the IHE integration profile can be useful in selecting a systems vendor that is compatible with operations throughout the facility, as well as for facilitating the decision to introduce such a system (1). Realistically, however, even after the decision to introduce a system has been made, development will be required before the system becomes operational and some time will be required.

Figure 7 shows a flow chart tracking the introduction of an appointment order entry system for nuclear medicine tests until the system becomes operational. After the decision to introduce the system has been made, system development is conducted before the operation is begun. The following 3 development processes are possible. Type 1: Operation is initiated without holding any meetings during the development stages. Type 2: A meeting is held to explain the system specifications after development, but specifications are already fixed and shall not be altered. Type 3: In-depth meetings are held during each developmental stage, during which 
TABLE 4

Setting of Confinement Between Test Items

\begin{tabular}{|c|c|c|c|c|c|c|c|}
\hline \multicolumn{8}{|c|}{ Confined values between MRI tests (total set number: 8,100 ) } \\
\hline $\begin{array}{l}\text { Baseline test items } \\
\text { (MRI: } 90 \text { items) }\end{array}$ & \multicolumn{2}{|c|}{$\begin{array}{l}\text { Subject group } \\
\text { (MRI: } 90 \text { setting) }\end{array}$} & \multicolumn{2}{|c|}{$\begin{array}{l}\text { Time required } \\
\text { for tests }\end{array}$} & \multicolumn{2}{|c|}{ Set value } & Confined value \\
\hline \multirow[t]{5}{*}{ MRI head plain } & \multicolumn{2}{|c|}{ MRI head plain } & \multicolumn{2}{|l|}{$10 \mathrm{~min}$} & \multicolumn{2}{|c|}{$1 \mathrm{~h}$} & $1 \mathrm{~h} 10 \mathrm{~min}$ \\
\hline & \multicolumn{2}{|c|}{ MRI pituitary plain } & \multicolumn{2}{|l|}{$10 \mathrm{~min}$} & \multicolumn{2}{|c|}{ Absence } & $10 \mathrm{~min}$ \\
\hline & \multicolumn{2}{|c|}{ MRI accesory sinus cavity plain } & \multicolumn{2}{|l|}{$10 \mathrm{~min}$} & \multicolumn{2}{|c|}{ Absence } & $10 \mathrm{~min}$ \\
\hline & \multicolumn{2}{|c|}{ MRI head contrast } & \multicolumn{2}{|l|}{$20 \mathrm{~min}$} & \multicolumn{2}{|c|}{ Absence } & $20 \mathrm{~min}$ \\
\hline & \multicolumn{2}{|c|}{ MRI pituitary contrast } & \multicolumn{2}{|l|}{$20 \mathrm{~min}$} & \multicolumn{2}{|c|}{ Absence } & $20 \mathrm{~min}$ \\
\hline \multirow{5}{*}{ MRI head contrast } & \multicolumn{2}{|c|}{ MRI head plain } & \multicolumn{2}{|l|}{$20 \mathrm{~min}$} & \multicolumn{2}{|c|}{ Absence } & $20 \mathrm{~min}$ \\
\hline & \multicolumn{2}{|c|}{ MRI pituitary plain } & \multicolumn{2}{|l|}{$20 \mathrm{~min}$} & \multicolumn{2}{|c|}{ Absence } & $20 \mathrm{~min}$ \\
\hline & MRI head & ntrast & $20 \min$ & & 1 & & $1 \mathrm{~d} 20 \mathrm{~min}$ \\
\hline & MRI pituita & contrast & $20 \min$ & & 1 & & $1 \mathrm{~d} 20 \mathrm{~min}$ \\
\hline & MRI acces & y sinus cavity contrast & $20 \min$ & & 1 & & $1 \mathrm{~d} 20 \mathrm{~min}$ \\
\hline & Conf & ed values between NM t & ts (total set num & hber: 6,4 & & & \\
\hline Baseline test items & & ubject group & Time required & $\mathrm{Se}$ & value & Confin & ined value \\
\hline (NM: 57 items) & & И: 57 setting) & for tests & Past & Future & Past & Future \\
\hline Thyroid $\left({ }^{99 m} \mathrm{TcO}_{4}{ }^{-}\right)$ & Thyroid $(99 \mathrm{~m}$ & $\left.\mathrm{O}_{4}^{-}\right)$ & $30 \mathrm{~min}$ & $2 d$ & $2 d$ & $2 \mathrm{~d} 30 \mathrm{~min}$ & $2 \mathrm{~d} 30 \mathrm{~min}$ \\
\hline & Bone adult/v & ole body (99mTc-HMDP) & $30 \mathrm{~min}$ & $2 d$ & $2 \mathrm{~d}$ & $2 \mathrm{~d} 30 \mathrm{~min}$ & $2 \mathrm{~d} 30 \mathrm{~min}$ \\
\hline & ${ }^{67} \mathrm{Ga}$ adult/w & ole body ( ${ }^{67} \mathrm{Ga}$-citrate) & $30 \mathrm{~min}$ & $4 d$ & $4 \mathrm{~d}$ & $4 \mathrm{~d} 30 \mathrm{~min}$ & $4 \mathrm{~d} 30 \mathrm{~min}$ \\
\hline Bone adult/whole body & Thyroid $(99 \mathrm{~m}-$ & $\left.\mathrm{O}_{4}^{-}\right)$ & $10 \mathrm{~min}$ & $2 d$ & $2 d$ & $2 \mathrm{~d} 10 \mathrm{~min}$ & $2 \mathrm{~d} 10 \mathrm{~min}$ \\
\hline (99mTc-HMDP) & Bone adult/v & ole body (99mTc-HMDP) & $10 \mathrm{~min}$ & $2 d$ & $2 d$ & $2 \mathrm{~d} 10 \mathrm{~min}$ & $2 \mathrm{~d} 10 \mathrm{~min}$ \\
\hline & ${ }^{67} \mathrm{Ga}$ adult/w & ole body ( ${ }^{67} \mathrm{Ga}$-citrate) & $10 \mathrm{~min}$ & $4 \mathrm{~d}$ & $4 \mathrm{~d}$ & $4 \mathrm{~d} 10 \mathrm{~min}$ & $4 \mathrm{~d} 10 \mathrm{~min}$ \\
\hline${ }^{67} \mathrm{Ga}$ adult/whole body & Thyroid $(99 \mathrm{~m}$ & $\left.\mathrm{O}_{4}^{-}\right)$ & $10 \mathrm{~min}$ & $4 \mathrm{~d}$ & $4 \mathrm{~d}$ & $4 \mathrm{~d} 10 \mathrm{~min}$ & $4 \mathrm{~d} 10 \mathrm{~min}$ \\
\hline ( ${ }^{67} \mathrm{Ga}$-citrate) & Bone adult/v & ole body (99mTc-HMDP) & $10 \mathrm{~min}$ & $4 \mathrm{~d}$ & $4 \mathrm{~d}$ & $4 \mathrm{~d} 10 \mathrm{~min}$ & $4 \mathrm{~d} 10 \mathrm{~min}$ \\
\hline & ${ }^{67} \mathrm{Ga}$ adult/w & ole body ( ${ }^{7} \mathrm{Ga}$-citrate) & $10 \mathrm{~min}$ & $6 \mathrm{~d}$ & $6 \mathrm{~d}$ & $6 \mathrm{~d} 10 \mathrm{~min}$ & $6 \mathrm{~d} 10 \mathrm{~min}$ \\
\hline & Confined val & es between NM tests and & MRI tests (total s & set numb & $r: 10,26$ & & \\
\hline $\begin{array}{l}\text { Baseline test it } \\
\text { (NM: } 57 \text { items) (MRI }\end{array}$ & $\begin{array}{l}\mathrm{ms} \\
90 \text { items) }\end{array}$ & $\begin{array}{r}\text { Subject grou } \\
\text { (MRI: } 90 \text { setting) (NM: }\end{array}$ & 57 setting) & $\begin{array}{l}\text { Time re } \\
\text { for te }\end{array}$ & dired & Set value & Confined value \\
\hline Thyroid $\left({ }^{\left.99 m \mathrm{TcO}_{4}{ }^{-}\right)}\right.$ & & MRI head plain & & $30 n$ & & $1 \mathrm{~h}$ & $1 \mathrm{~h} 30 \mathrm{~min}$ \\
\hline & & MRI head angiogram pla & & $30 n$ & & $1 \mathrm{~h}$ & $1 \mathrm{~h} 30 \mathrm{~min}$ \\
\hline Bone adult/whole body & 9mTc-HMDP) & MRI head plain & & $10 n$ & & Absence & $10 \mathrm{~min}$ \\
\hline & & MRI head angiogram pla & & $10 n$ & & Absence & $10 \mathrm{~min}$ \\
\hline Ga adult/whole body (67 & a-citrate) & MRI head plain & & $10 n$ & & Absence & $10 \mathrm{~min}$ \\
\hline & & MRI head angiogram pla & & $10 n$ & & Absence & $10 \mathrm{~min}$ \\
\hline MRI head plain & & Bone adult/whole body & 9mTc-HMDP) & $10 n$ & & Absence & $10 \mathrm{~min}$ \\
\hline & & ${ }^{67} \mathrm{Ga}$ adult/whole body & Ga-citrate) & $10 n$ & & Absence & $10 \mathrm{~min}$ \\
\hline MRI head contrast & & Bone adult/whole body & 9mTc-HMDP) & $20 n$ & & Absence & $20 \mathrm{~min}$ \\
\hline & & ${ }^{67} \mathrm{Ga}$ adult/whole body & Ga-citrate) & $20 n$ & & Absence & $20 \mathrm{~min}$ \\
\hline clear medicin & & & & & & & \\
\hline
\end{tabular}

changes can be made. In the case of nuclear medicine tests, which require specialized operations, the operations cannot be tied together unless the type 3 development process is used to support the online operation of patient information and test order information from the order entry system. Therefore, it is essential that the development vendor understands the content and operation of nuclear medicine tests.

For MRI and CT at the radiology department, online operation of patient information and test order information from the order entry system can reportedly maintain consistency of information throughout the facility and enable uniform management of patient information $(16,17)$. However, because specialized operations are used in nuclear medicine tests, online sharing of patient information and test order information from the order entry system-as shown by SWF-is difficult, reportedly making information throughout the facility inconsistent and uniform management of patient information impossible. Therefore, we examined order entry systems that are considered important for patient information management when nuclear medicine tests are scheduled and are also consistent throughout the facility.

\section{Exclusion Settings}

In creating the exclusion settings for nuclear medicine tests, it was necessary for medical technicians to configure settings for the test items used on the order screen of the 
TABLE 5

Test Items Corresponding to Appointed Test Frames of NM Tests

\begin{tabular}{|c|c|}
\hline Appointed test frames & Test items \\
\hline Bone test frame & 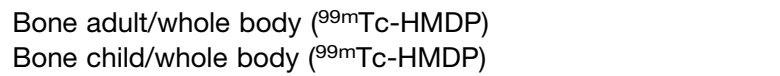 \\
\hline Brain test frame & $\begin{array}{l}\text { CBF (123/-IMP) } \\
\text { Load of CBF }\left({ }^{123} / \text {-IMP) }\right. \\
\text { Brain }\left({ }^{99 m} \text { Tc-ECD) }\right. \\
\text { Brain tank }\left({ }^{111} \mid \mathrm{ICl}_{3}\right) \\
\text { Encephalon }\left({ }^{111} \mathrm{In}-\mathrm{DTPA}\right)\end{array}$ \\
\hline Circulatory organ resting test frame & $\begin{array}{l}\text { Myocardial fatty acid metabolism }\left({ }^{123} \text { I-BMIPP) }\right. \\
\text { Myocardial sympathetic nerve activity }\left({ }^{123} \mid-M I B G\right) \\
\text { Myocardial blood flow at resting }\left({ }^{201} \mathrm{TICI}\right)\end{array}$ \\
\hline Circulatory organ resting QGS test frame & Myocardial blood flow at resting (99mTc-MIBI) \\
\hline Circulatory organ exercising test frame & 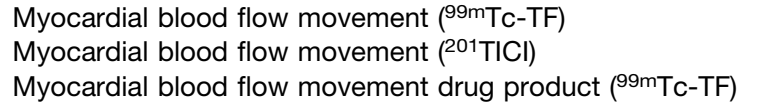 \\
\hline Urinary system test frame & $\begin{array}{l}\text { Renal function/RPF (99mTc-MAG3) } \\
\text { Renal function/GFR ( } 99 \mathrm{~m} \text { Tc-DTPA) } \\
\text { Kidney (99mTc-DMSA) }\end{array}$ \\
\hline Respiratory system test frame & 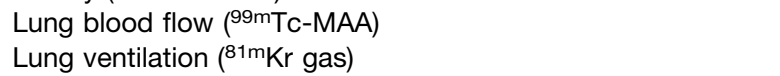 \\
\hline Angiograph system test frame & 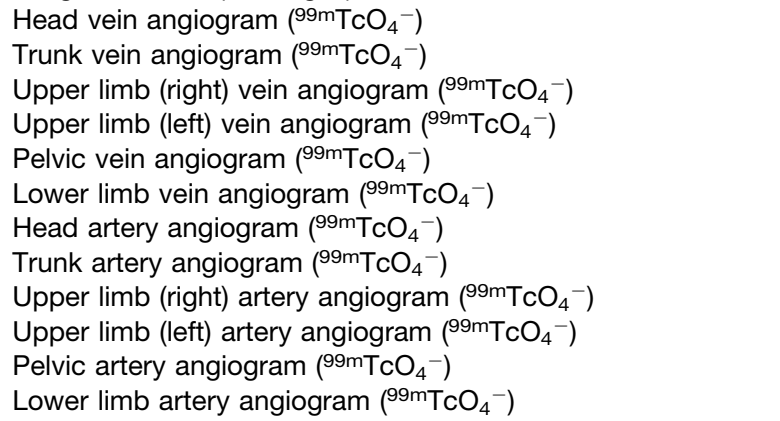 \\
\hline Bone $+{ }^{67} \mathrm{Ga}$ test frame & $\begin{array}{l}\text { Bone }+{ }^{67} \mathrm{Ga} \text { adult/whole body }\left({ }^{99 \mathrm{~m} T c-H M D P}+{ }^{67} \mathrm{Ga} \text {-citrate) }\right. \\
\text { Bone }+{ }^{67} \mathrm{Ga} \text { child/whole body ( }{ }^{99 \mathrm{~m} T c-H M D P}+{ }^{67} \mathrm{Ga} \text {-citrate) } \\
{ }^{67} \mathrm{Ga} \text { adult/whole body ( }{ }^{67} \mathrm{Ga} \text {-citrate) } \\
{ }^{67} \mathrm{Ga} \text { child/whole body ( }{ }^{67} \mathrm{Ga} \text {-citrate) }\end{array}$ \\
\hline Tumor (201TI) test frame & Tumor $\left({ }^{201} \mathrm{TICl}\right)$ \\
\hline Digestive system test frame & $\begin{array}{l}\text { Liver function ( }{ }^{99 m T c-G S A)} \\
\text { Liver/biliary tract ( }{ }^{99 m T c-P M T)} \\
\text { Liver ( }{ }^{99 m T c-S n-c o l l o i d) ~}\end{array}$ \\
\hline Endocrine test frame & 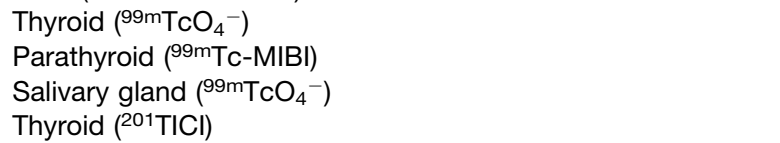 \\
\hline Pheo-scintigraphy test frame & Pheo-scintigraphy ( ${ }^{131}$ I-Pheo-MIBG) \\
\hline Intake rate in thyroid test frame & Intake rate in thyroid ( $\mathrm{Na}^{123}$ capsule) \\
\hline Adosterol test frame & Adosterol (131|-adosterol) \\
\hline Hematopoietic system test frame & $\begin{array}{l}\text { Spleen ( }{ }^{99 m} \text { Tc-Sn-colloid) } \\
\text { Amount of circulating blood } \\
\text { Erythrocyte life span }\end{array}$ \\
\hline Nuclear medical test frame at a later date & $\begin{array}{l}\text { Adosterol at a later date } \\
{ }^{67} \mathrm{Ga} \text { photograph adult at a later date } \\
\text { Intake rate in thyroid at a later date } \\
\text { Pheo-scintigraphy at a later date } \\
\text { Gastrointestinal bleeding at a later date } \\
\text { Bone marrow at a later date } \\
\text { Brain tank at a later date }\end{array}$ \\
\hline Emergent test frame & 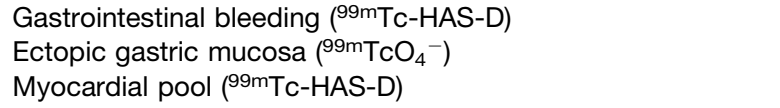 \\
\hline Demand test frame & All test items \\
\hline
\end{tabular}




\begin{tabular}{|c|c|c|c|c|c|}
\hline $\begin{array}{l}\text { A } \\
\text { MRI test }\end{array}$ & \multicolumn{5}{|c|}{ Nuclear medical test: In case of one $\gamma$-camera } \\
\hline $\begin{array}{c}\text { MRI test } \\
\text { frame }\end{array}$ & $\begin{array}{c}\text { Bone test } \\
\text { frame }\end{array}$ & $\begin{array}{c}\text { Brain test } \\
\text { frame }\end{array}$ & \multirow{2}{*}{$\begin{array}{c}\text { Circulatory } \\
\text { organ } \\
\text { resting test } \\
\text { frame }\end{array}$} & \multirow{3}{*}{\begin{tabular}{|c|}
$\begin{array}{c}\text { Circulatory } \\
\text { organ } \\
\text { resting } \\
\text { QGS test } \\
\text { frame }\end{array}$ \\
0.00 \\
\end{tabular}} & \multirow{2}{*}{$\begin{array}{c}\text { Circulatory } \\
\text { organ } \\
\text { exercising } \\
\text { test frame }\end{array}$} \\
\hline $9: 00$ & $9: 00$ & $9: 00$ & & & \\
\hline $9: 10$ & - & $10: 00$ & $9: 00$ & & $9: 00$ \\
\hline $9: 20$ & $11: 00$ & - & $11: 00$ & & $10: 00$ \\
\hline $9: 30$ & \multirow[t]{2}{*}{ Mon.-Fri. } & $13: 00$ & \multirow[t]{2}{*}{ Tue. } & $9: 30$ & $11: 00$ \\
\hline $9: 40$ & & Mon., Wed. & & Tue., Thur. & Thur. \\
\hline $9: 50$ & \multirow{2}{*}{$\begin{array}{c}\text { Urinary } \\
\text { system } \\
\text { test frame }\end{array}$} & \multirow{2}{*}{$\begin{array}{c}\text { Respiratory } \\
\text { system } \\
\text { test frame } \\
\end{array}$} & \multirow{2}{*}{\begin{tabular}{|c|} 
Angiograph \\
system test \\
frame \\
\end{tabular}} & \multirow{2}{*}{\begin{tabular}{|c|} 
Bone $+{ }^{67} \mathrm{Ga}$ \\
test frame \\
\end{tabular}} & \multirow{2}{*}{$\begin{array}{c}\text { Tumor } \\
(201 \mathrm{TI}) \text { test } \\
\text { frame }\end{array}$} \\
\hline $10: 00$ & & & & & \\
\hline $10: 10$ & $11: 00$ & $11: 00$ & $14: 00$ & 10:00 & $9: 00$ \\
\hline$\downarrow$ & - & $11: 30$ & \multirow[t]{3}{*}{ Mon.-Fri. } & \multirow[t]{3}{*}{ Mon., Tue. } & \multirow[t]{3}{*}{ Fri. } \\
\hline $10: 50$ & $13: 00$ & \multirow[t]{2}{*}{ Mon. } & & & \\
\hline$\downarrow$ & Tue. & & & & \\
\hline $11: 40$ & \multirow{2}{*}{$\begin{array}{l}\text { Digestive } \\
\text { system } \\
\text { test frame }\end{array}$} & \multirow{2}{*}{$\begin{array}{c}\text { Endocrine } \\
\text { system } \\
\text { test frame }\end{array}$} & \multirow{2}{*}{$\begin{array}{c}\text { Pheo } \\
\text { scinitigraphy } \\
\text { test frame }\end{array}$} & \multirow{2}{*}{$\begin{array}{l}\text { Intake rate } \\
\text { in thyroid } \\
\text { test frame }\end{array}$} & \multirow{2}{*}{$\begin{array}{l}\text { Adosterol } \\
\text { test frame }\end{array}$} \\
\hline $11: 50$ & & & & & \\
\hline- & $11: 00$ & $11: 30$ & $10: 00$ & $10: 00$ & 10:00 \\
\hline $12: 50$ & Wed. & Wed. & Tue. & Tue. & \multirow[b]{10}{*}{ e gated SPECT } \\
\hline$\downarrow$ & $\begin{array}{l}\text { Hemato- } \\
\text { poietic }\end{array}$ & $\begin{array}{l}\text { Nuclear } \\
\text { medical }\end{array}$ & $\begin{array}{l}\text { Emergent } \\
\text { test frame }\end{array}$ & $\begin{array}{l}\text { Demand } \\
\text { test frame }\end{array}$ & \\
\hline & \begin{tabular}{|c|} 
test frame \\
10.00
\end{tabular} & at a later & $9: 00$ & $9: 00$ & \\
\hline $16: 40$ & 10:00 & date & $10: 00$ & $10 \cdot 10$ & \\
\hline $16: 50$ & Wed. & 9:00 & & 10.00 & \\
\hline Mon.-Fri. & & $9: 30$ & $11: 00$ & $11: 00$ & \\
\hline & & $\downarrow$ & $\downarrow$ & $\downarrow$ & \\
\hline & & $16: 00$ & $16: 00$ & $16: 00$ & \\
\hline & & $16: 30$ & Mon.-Fri. & Mon.-Fri. & \\
\hline & & Mon.-Fri. & & QGS:quantit & \\
\hline
\end{tabular}

FIGURE 4. Example: Appointed test frame. In case of setting of time series (A), it is possible to set the same frame from Monday through Friday during routine work. In case of setting groups (B), it is necessary to set frames based on an operation form for each day.
In setting the test items for nuclear medicine tests, it was thought better not to just transfer the test names used on paper requests before the introduction of an order entry system but also to have the technicians in charge of the modality and the
FIGURE 5. Example: Methods of obtaining appointment for nuclear medical test in which setting of appointed test frame is conducted between groups. Setting of confinement: methods for obtaining groups between test items.

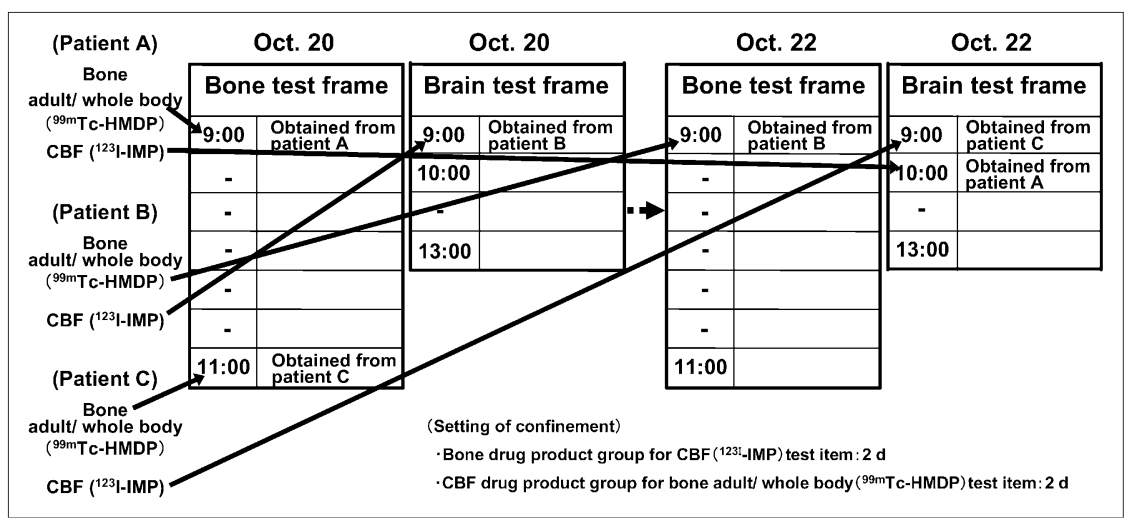




\begin{tabular}{|l||c|c|c|c|c|c|}
\hline (Patient A) & Oct. 20 \\
MRI head \\
contrast
\end{tabular}

FIGURE 6. Example: Methods for obtaining appointment of nuclear medical test in group setting and MRI test in time series setting. Setting of confinement: methods for obtaining groups between test items. ordering physicians confirm that it is a test that can be conducted in the system operation and change to the system test name. This was done to avoid confusion in test item names on the order side during the system operation. When a new nuclear medicine test becomes operational, it was thought appropriate to consider knowledge on the order side of nuclear medicine tests and set a name based on nuclear medicine technical books.

In setting the time required for the test items in nuclear medicine, there are cases in which the test is conducted immediately after the tracer injection and cases in which the test is conducted some time after the tracer injection. Therefore, for nuclear medicine tests, unlike MRI, the date and time of the test item obtained from the order entry system was not considered the test starting time but, rather, the date and time that the patient came to the testing room, and the time required for data acquisition and time required for injection had to be classified. Further, the interval until data acquisition after injection for test items classified by the time required for injection had to be adjusted on the basis of the appointment frame and operation time of the apparatus.

In group classification of nuclear medicine test items, these items cannot be classified like MRI tests based simply on the use of a contrast agent into 2 groups of plain imaging and contrast-enhanced imaging because of the specialized content of nuclear medicine tests. Therefore, it was necessary to decide the classification of each nuclear medicine test on the basis of the radiopharmaceuticals used and the test items.

Although in the group classifications in our study, bone adult/whole body ( ${ }^{99 \mathrm{~m}}$ Tc-HMDP) and bone child/whole body ( $\left.{ }^{99 \mathrm{~m}} \mathrm{Tc}-\mathrm{HMDP}\right)$ in the bone drug product group were considered to essentially belong to the ${ }^{99 \mathrm{~m}} \mathrm{Tc}$ drug product group, it was necessary to set them in separate groups because the operations and appointment frames for these items differed from tests belonging to the ${ }^{99 \mathrm{~m}} \mathrm{Tc}$ drug product group.

The later data acquisition group was set because it is necessary to supply the information on the appointment time

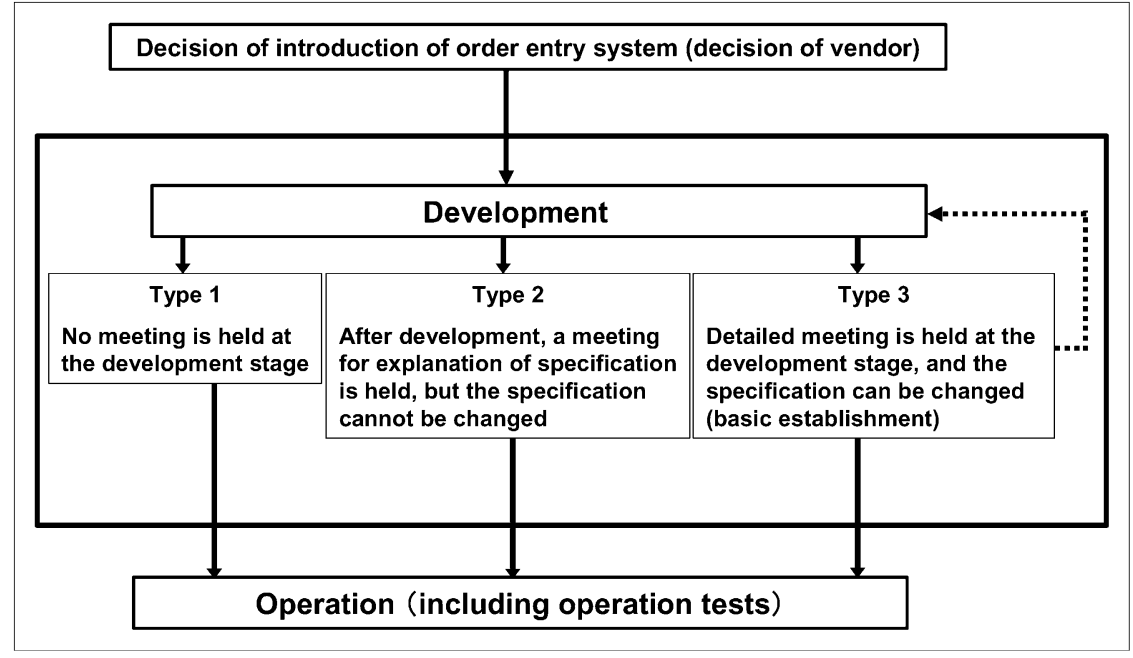

FIGURE 7. Flow from introduction to operation (outline). 
of the test after injection throughout the facility for items such as adosterol ( ${ }^{131} \mathrm{I}$-adosterol) and pheo-scintigraphy ( ${ }^{131}$ I-pheo-metaiodobenzylguanidine [MIBG]) that belong to the later collection group.

The methods for exclusion settings include setting between test item groups, setting between groups, and setting between test items.

In the method of setting between test item groups, excluded values are set for a subject group against a standard test item. Because exclusion settings are configured for a subject group from each test item, this is a method by which detailed settings can be configured for test items.

In the method of setting between groups, excluded values are set for a subject group against a standard group. Because excluded values are set for entire groups in this method, the number of settings is small and exclusion settings can easily be configured, but detailed exclusion settings for test items cannot be configured by this method.

In the method of setting between test items, excluded values for a subject test item are set against a standard test item. Since this method is conducted one-on-one between each test item, even more detailed settings can be configured by this method. However, the work needed for its development is more complicated than the method of setting between groups or setting between test item groups for setting exclusion items.

When deciding the excluded values for the exclusion settings, values were set at zero to enable the acquisition of sequential tests in the same modality. However, considering the time required for the patient to be moved to another testing room, it may be better to include the moving time in the excluded value.

Henceforth, expected test items will be excluded on the basis of the time of the scheduled test items in the excluded values set by each method. However, when scheduling nuclear medicine tests, exclusion was also necessary for previous tests, because the radiopharmaceuticals used in previously conducted tests could affect subsequent nuclear medicine test results.

The exclusion settings configured in this study were settings for nuclear medicine tests and MRI tests, which would amount to an enormous number of settings between modalities at the radiology department. Therefore, creating settings between test item groups seems to be the most suitable method for exclusion settings in an order entry system, which would allow configuration of detailed exclusion settings and allow good efficiency, such as in postoperational system maintenance. However, if an order entry system that does not include these exclusion settings as standard features is planned to be introduced, detailed discussion with the vendor will probably be necessary.

\section{Appointment Frame Settings}

As methods for setting appointment frames, only a single frame is set for the appointment frame of modality and the appointment frame of the acquisition in the routine work from Monday to Friday is set in the same appointment frame, 1 or more frames are set for the appointment frame of modality, and appointment frames are set on the basis of the acquisition frame of test appointments for routine work from Monday to Friday as well as the types of operation.

Time series settings are thought to be usable for appointment frames in cases such as MRI tests, in which tests can be started at the appointed hour, irrespective of whether the test would involve plain or contrast-enhanced imaging. However, when tests cannot be started at the appointed hour time depending on the test item, as with nuclear medicine tests, it is thought to be necessary to use group settings for appointment frames and to set appointment frames for each corresponding test item, on the basis of the operations in routine work from Monday to Friday.

In this study, we have discussed methods for setting exclusion settings and appointment frames that are necessary when introducing an appointment order entry system. Exclusion settings are needed when the test for appointment is conducted at the place of treatment, and in the operation of order entry systems in which exclusion settings cannot be configured, someone who understands the test content well can make appointments and prevent overlaps. However, when someone who does not understand the test content makes appointments, overlapping appointments are likely to occur, which can affect not only the patient but also the operation of the entire facility. Moreover, the same kind of effect is expected not only in the appointment order entry systems but also in treatment order entry systems that need exclusion settings. In setting appointment frames, it is considered necessary to understand the operations of each modality and to set the appointment frames to conduct tests efficiently.

It is believed that online sharing of patient information and test order information from an order entry system of SWF defined by IHE is possible if an order entry system with exclusion settings and appointment frames as standard features is introduced.

\section{CONCLUSION}

To establish uniform management of patient information for nuclear medicine tests throughout the facility, it is necessary to develop an order entry system with exclusion settings and appointment frames as standard features. Thereby, it is thought that integration of health information with RIS or PACS that are based on DICOM standards and real-time health care assistance that can realize the IHE agenda of improving health care service and efficiently supply information are possible.

\section{ACKNOWLEDGMENTS}

The authors thank Kayo Hara and all of the radiological technologists of Sumitomo Hospital for their technical support. 


\section{REFERENCES}

1. NEMA Standard Publication PS3.3-1993, Digital Imaging and Communications in Medicine (DICOM). Part 3: Information Object Definitions. Available at: http://www.medical.nema.org/dicom. Accessed November 2, 2007.

2. NEMA Standard Publication PS3.3-2000, Digital Imaging and Communications in Medicine (DICOM). Part 3: Information Object Definitions. Available at: http://www.medical.nema.org/dicom. Accessed November 2, 2007.

3. HL7 Standard Version 2.4. 2000. Available at: http://www.hl7.org. Accessed November 2, 2007.

4. HL7 Standard Version 2.4 Japan. 2002. Available at: http://www.hl7.jp. Accessed November 2, 2007.

5. Kinsey TV, Horton MC, Lewis TE. Interfacing the PACS and the HIS results of a 5-year implementation. Radiographics. 2000;20:883-891.

6. Fernandez-Bayo J, Barbero O, Rubies C, et al. Distributing medical images with internet technologies: a DICOM Web server and a DICOM Java viewer. Radiographics. 2000;20:581-590.

7. Nanni M, Carnassale R, Napoli M, et al. Information systems in the management of the radiology department. Rays. 2003;28:63-72.

8. Boochever SS. HIS/RIS/PACS integration: getting to the gold standard. Radiol Manage. 2004;26:16-27.
9. Siegel EL, Channin DS. Integrating the healthcare enterprise: a primer. Part 1. Introduction. Radiographics. 2001;21:1339-1341.

10. Channin DS. Integrating the healthcare enterprise: a primer. Part 2. Seven brides for seven brothers - the IHE integration profiles. Radiographics. 2001;21:1343-1350.

11. Channin DS, Parisot C, Wanchoo V, et al. Integrating the healthcare enterprise: a primer. Part 3. What does IHE do for me? Radiographics. 2001;21:1351-1358.

12. Henderson M, Behlen FM, Parisot $\mathrm{C}$, et al. Integrating the healthcare enterprise: a primer. Part 4. The role of existing standards in IHE. Radiographics. 2001;21: 1597-1603.

13. Channin DS, Siegel EL, Carr C, et al. Integrating the healthcare enterprise: a primer. Part 5. The future of IHE. Radiographics. 2001;21:1605-1608.

14. Channin DS. Integrating the healthcare enterprise: a primer. Part 6 . The fellowship of IHE-year 4 additions and extensions. Radiographics. 2002;22:1555-1560.

15. Hara N, Honda M, Yuhi M, et al: Developmental process of a reservation inspection ordering system in the radiology department. Med J Sumitomo Hosp. 2004;31:9-16.

16. Moore SM. Using the IHE scheduled work flow integration profile to drive modality efficiency. Radiographics. 2003;23:523-529.

17. Bernardini A, Alonzi M, Campioni P, et al. IHE: integrating the healthcare enterprise-towards complete integration of healthcare information systems. Rays. 2003;28:83-93. 